\title{
C677T methylenetetrahydrofolate reductase gene polymorphism as a risk factor involved in venous thromboembolism: A population-based case-control study
}

\author{
GUANCHENG YIN ${ }^{1,2}$, LIQING YAN $^{3}$, ZHIFENG ZHANG $^{4}$, KEBIAO CHEN $^{2}$ and XING JIN ${ }^{1}$ \\ ${ }^{1}$ Department of Vascular Surgery, Shandong Provincial Hospital, Shandong University, Jinan 250012; \\ Departments of ${ }^{2}$ Cardiovascular Surgery, ${ }^{3}$ Gynaecology and ${ }^{4}$ Laboratory, \\ The Central Hospital of Taian, Taian 271000, P.R. China
}

Received April 17, 2012; Accepted September 7, 2012

DOI: $10.3892 / \mathrm{mmr} .2012 .1086$

\begin{abstract}
The aim of the current study was to investigate the possible correlation between the C677T methylenetetrahydrofolate reductase (MTHFR) polymorphism and venous thromboembolism (VTE) in a population-based case-control study. Homocysteine (Hcy) was quantified by Abbott IMx immunoassay; screening for C677T MTHFR substitution was performed by polymerase chain reaction (PCR) and restriction analysis. The results from the two groups (440 patients and 440 controls) revealed that the frequency of $\mathrm{T}$ alleles and TT carriers was significantly higher in patients compared with that of the healthy controls. The plasma levels of Hcy in the VTE group $(13.05 \pm 2.37 \mu \mathrm{mol} / \mathrm{l})$ were significantly higher compared with those in the control group $(11.94 \pm 2.03 \mu \mathrm{mol} / 1, \mathrm{P}<0.001)$. The C677T MTHFR polymorphism is suggested to be associated with the risk for VTE. Plasma levels of Hcy were raised in individuals with the homozygous MTHFR 677TT genotype. In conclusion, the results of the current study suggest that hyperhomocysteinemia and the homozygous 677TT MTHFR genotype are risk factors for VTE.
\end{abstract}

\section{Introduction}

Venous thromboembolism (VTE) is a major cause of morbidity and mortality. However, the mechanisms of the predisposition remain unclear. Mild or moderate hyperhomocysteinemia is a known risk factor for venous thrombophilia as a single disorder or in combined defects $(1,2)$. Hyperhomocysteinemia occurs due to a combination of genetic and environmental factors $(3,4)$. Several mutations or combined defects affecting

Correspondence to: Dr Xing Jin, Department of Vascular Surgery, Shandong Provincial Hospital, Shandong University, 44\# Wenhua Xi Road, Jinan 250012, P.R. China

E-mail: mjas2020@163.com

Key words: methylenetetrahydrofolate reductase, polymorphism, venous thromboembolism the homocysteine (Hcy) pathway have been reported $(5,6)$. A polymorphism, C677T, in the methylenetetrahydrofolate reductase (MTHFR) gene, is responsible for the Ala223Val substitution (7) in a highly conserved residue of the molecule. The substitution renders the enzyme thermolabile and has been recognized as a cause of intermediate hyperhomocysteinemia. Previous findings have revealed that subjects carrying the MTHFR mutation in a homozygous condition have significantly higher homocysteine levels than those of heterozygotes or normal homozygotes, particularly when folate levels are in the low-normal range (8). These subjects may be at increased risk of cardiovascular disease. However, not all previous studies have reported a direct association between the C677T mutation and VTE or arterial vascular disease. Therefore, the correlation between the C677T mutation and VTE or arterial vascular disease remains controversial. Moreover, the frequency of the mutated allele is high and the mutation has a significantly heterogeneous distribution among various ethnic groups. In the present population-based case-control study, we analyzed the frequency of the C677T polymorphism in the MTHFR gene of patients in China with VTE, in comparison with individuals without evidence of the disease. In addition, we evaluated the association between this polymorphism and plasma Hcy levels. The possible interactive effects of tobacco smoking with risk factors for VTE were also evaluated.

\section{Patients and methods}

Subjects. Between September 2008 and March 2010, 440 patients (211 males and 229 females) were diagnosed with lower extremity deep venous thrombosis (DVT) by duplex ultrasonography at Shandong Provincial Hospital, Shandong University (Jinan, China) and were recruited into the VTE group. The mean age was $44.7 \pm 7.5$ years (range, 28-90); 274 $(62.3 \%)$ were outpatients and $166(37.7 \%)$ were hospitalized patients. Patients with hematological diseases, liver or kidney dysfunction, infections, autoimmune diseases, tumors or those receiving thrombolytic treatment or anticoagulant treatment were excluded from this study. Venous thrombosis was localized to the left side in 298 patients $(67.7 \%)$, the right side in 
Table I. Characteristics of participants.

\begin{tabular}{lcccc}
\hline \multicolumn{5}{c}{ Controls (n=440) } \\
Characteristic & $\mathrm{n}(\%)$ & $\mathrm{n}(\%)$ & $\chi^{2}$ & P-value \\
\hline Age (years) & & & & \\
$>45$ & $193(43.9)$ & $178(40.5)$ & 1.049 & 0.306 \\
$\geq 45$ & $247(56.1)$ & $262(59.5)$ & & \\
Gender & & & & \\
Male & $236(53.6)$ & $211(52.0)$ & 2.842 & 0.092 \\
Female & $204(46.4)$ & $229(50.0)$ & & \\
\hline
\end{tabular}

The two groups were matched in age and gender.

125 patients $(28.4 \%)$ and both sides in 17 patients $(3.9 \%)$. A total of 16 patients had pulmonary embolism (PE; 3.6\%). A total of 440 healthy unrelated subjects who had no previous diagnoses of VTE or other associated diseases were recruited into the control group. The mean age of the control subjects was $46.3 \pm 7.6$ years (range, $21-82) ; 236(53.6 \%)$ of the healthy subjects were male and 204 (46.4\%) were female. The characteristics of the study population are shown in Table I. Informed consent was obtained from all study subjects and the study was approved by the Shandong University Research Ethics Committee, China.

Hcy determination and genotyping. Peripheral venous blood was obtained from each subject and promptly centrifuged (1,500 rpm for $10 \mathrm{~min}$ ) following collection. A DNA extraction kit (Qiagen, Crawley, UK) was used to extract genomic DNA, according to the manufacturer's instructions. The DNA was then stored at $-70^{\circ} \mathrm{C}$ until use. Total Hcy was quantified using the fluorescence polarization immunoassay (FPIA) on the IMx analyzer from Abbott Laboratories (Abbott Park, IL, USA). The IMx Hcy assay is based on the reduction of the plasma samples with dithiothreitol and the subsequent conversion of free Hcy to S-adenosyl Hcy by hydrolase in the presence of added adenosine. The sample and the tracer compete for binding to the monoclonal antibody. Following the reaction, the level of S-adenosyl Hcy was evaluated by a fluorescence polarization immunoassay. The intensity of the polarized light is inversely correlated with the plasma concentration of Hcy.

Genomic DNA was detected by real-time polymerase chain reaction (RT-PCR) amplification followed by digestion with the restriction enzyme HinFI, as described by Frosst et al (9). The primers were designed as previously reported (10) with the following sequences for sense, 5'-GCCCAGCCACTCACTGTTTTA-3'; and antisense, 5'-AGGACGGTGCGGTGAGAGTG-3', used in a total volume of $25 \mu \mathrm{l}$ for amplification. The cycling conditions for PCR were initiation for $5 \mathrm{~min}$ at $94^{\circ} \mathrm{C}$, followed by 30 cycles of $40 \mathrm{sec}$ denaturation at $94^{\circ} \mathrm{C}$, annealing at $56^{\circ} \mathrm{C}$ for $4 \mathrm{sec}$ and extension at $72^{\circ} \mathrm{C}$ for $12 \mathrm{sec}$. A final extension step for $7 \mathrm{~min}$ at $72^{\circ} \mathrm{C}$ was also carried out. The amplified products were stored at $4^{\circ} \mathrm{C}$ and were later mixed and buffered with restriction endonuclease HinFI. The products were then left overnight

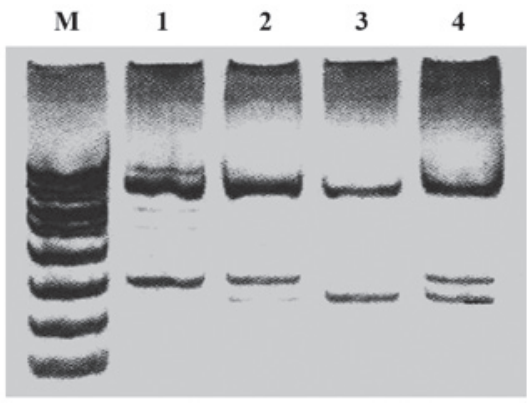

Figure 1. MTHFR gene C677T enzyme-cut electrophoresis with restriction endonuclease HinFI. M, DNA molecular weight marker. Lane 1, CC genotype; lanes 2 and 4, CT genotype; lane 3, TT genotype. MTHFR, methylenetetrahydrofolate reductase.

in a water bath kettle for digestion. Finally, all products were observed following the $8 \%$ polyacrylamide gel electrophoresis.

Statistical analysis. All statistical analyses were performed using SPSS 13.0 statistical software (SPSS Inc., Chicago, IL, USA) and data are presented as mean \pm standard deviation. Comparisons between two groups were performed by an independent t-test; Chi-square analysis was applied to determine the difference in the genotype and gene frequency. Odds ratios (ORs) and $95 \%$ confidence intervals (95\% CIs) were calculated from unconditional logistic regression models. A value of $\mathrm{P}<0.05$ was considered to indicate a statistically significant result.

\section{Results}

TT genotype is significantly correlated with an increased risk of VTE. Subjects homozygous for the mutation exhibited two DNA fragments 175 and 23 bp in length in electrophoresis, whereas homozygous subjects without the mutation exhibited a DNA fragment of 198-bp. Heterozygous subjects exhibited three DNA fragments of 198, 175 and 23 bp. Fig. 1 shows the polyacrylamide gel electrophoresis with restriction endonuclease HinFI. There were 3 genotypes, CC, CT and TT, in the MTHFR gene at position 677 in the two groups. Table II shows that the distribution of the MTHFR C677T gene polymorphisms in the controls were in a state of Hardy-Weinberg equilibrium. Table III shows the MTHFR C677T genotype frequencies and allele frequencies between the two groups. The frequencies of the $\mathrm{C}$ and $\mathrm{T}$ alleles were 47.4 and $52.6 \%$ in the VTE group and 63.1 and $36.9 \%$ in the controls, respectively $\left(\chi^{2}, 47.698 ; \mathrm{P}<0.01\right)$. The MTHFR C677T frequencies of the CC, CT and TT genotypes were $38.5,35.7$ and $25.5 \%$ in the VTE group and 41.4, 43.2 and $15.5 \%$ in the controls, respectively $\left(\chi^{2}, 14.237 ; \mathrm{P}=0.001\right)$. Table IV shows that, compared with the CC genotype, the TT genotype was significantly correlated with an increased risk of VTE (OR, 1.753; 95\% CI, 1.215-2.529; $\mathrm{P}=0.003)$.

Plasma levels of Hcy are increased in patients with VTE. The plasma level of Hcy in the VTE group $(13.05 \pm 2.37 \mu \mathrm{mol} / \mathrm{l})$ was significantly higher than that in the control group $(11.94 \pm 2.03 \mu \mathrm{mol} / 1, \mathrm{P}<0.001)$. Levels of Hcy among various 
Table II. MTHFR C677T genotype distribution in Hardy-Weinberg equilibrium. ${ }^{\mathrm{a}}$

\begin{tabular}{lcccc}
\hline Gene & Genotype & Predicted value, n (\%) & Observed value, n (\%) & $\chi^{2}$ \\
\hline MTHFRC677T & CC & $175(39.8)$ & $182(41.4)$ & 1.207 \\
& CT & $205(46.6)$ & $190(43.2)$ & 0.547 \\
& TT & $60(13.6)$ & $68(15.5)$ & \\
\hline
\end{tabular}

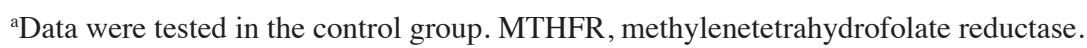

Table III. MTHFR C677T genotype frequency and allele frequency between the two groups.

\begin{tabular}{lcccc}
\hline $\begin{array}{l}\text { Genotypes } \\
\text { and alleles }\end{array}$ & $\begin{array}{c}\text { Controls } \\
\mathrm{n}(\%)\end{array}$ & $\begin{array}{l}\text { Cases } \\
\mathrm{n}(\%)\end{array}$ & $\chi^{2}$ & P-value \\
\hline $\mathrm{C}$ & $557(63.1)$ & $499(47.4)$ & 47.698 & $<0.001$ \\
$\mathrm{~T}$ & $326(36.9)$ & $554(52.6)$ & & \\
$\mathrm{CC}$ & $182(41.4)$ & $171(38.9)$ & 14.237 & 0.001 \\
$\mathrm{CT}$ & $190(43.2)$ & $157(35.7)$ & & \\
$\mathrm{TT}$ & $68(15.5)$ & $112(25.5)$ & & \\
\hline
\end{tabular}

Frequencies of T alleles and TT carriers was significantly higher in patients than among the healthy controls. MTHFR, methylenetetrahydrofolate reductase.

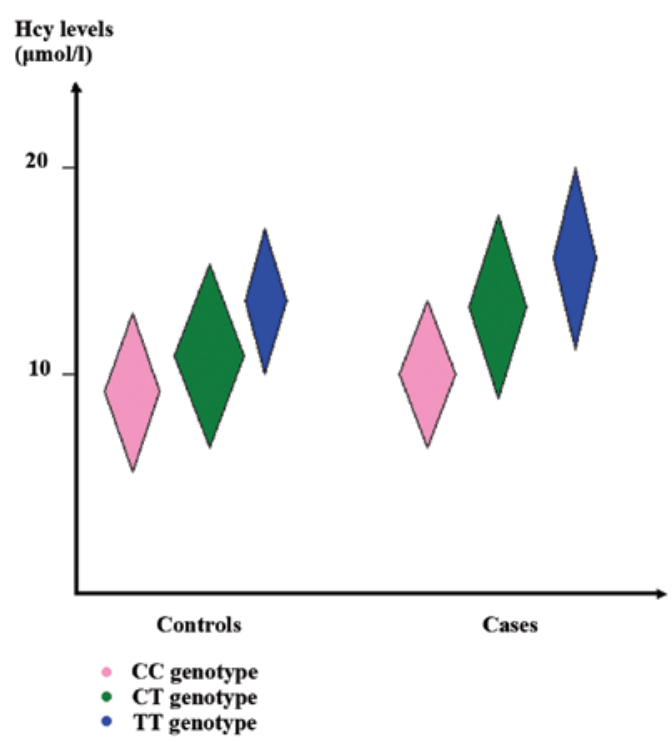

Figure 2. MTHFR C677T frequencies of CC, CT and TT genotypes were $38.5,35.7$ and $25.5 \%$ in the VTE group and $41.4,43.2$ and $15.5 \%$ in the controls, respectively. In the two groups, the level of Hcy in subjects with the TT genotype or CT genotype was higher than that in subjects with the CC genotype. The plasma level of Hcy in the VTE group $(13.05 \pm 2.37 \mu \mathrm{mol} / \mathrm{l})$ was significantly higher than that in the control group $(11.94 \pm 2.03 \mu \mathrm{mol} / 1$, $\mathrm{P}<0.001)$. MTHFR, methylenetetrahydrofolate reductase; VTE, venous thromboembolism; Hcy, homocysteine.

genotypes are shown in Table V. In the VTE group ( $\mathrm{F}=106.051$; $\mathrm{P}<0.001)$, the level of Hcy in subjects with the CT+TT genotype $(14.49 \pm 2.51 \mu \mathrm{mol} / \mathrm{l})$ was significantly higher than that in subjects with the $\mathrm{CC}$ genotype $(11.35 \pm 1.57 \mu \mathrm{mol} / 1, \mathrm{P}<0.001)$.
In the control group $(\mathrm{F}=100.362 ; \mathrm{P}<0.001)$, the level of Hcy in subjects with the CT+TT genotype $(12.08 \pm 3.53 \mu \mathrm{mol} / \mathrm{l})$ was significantly higher than that in subjects with the CC genotype $(10.03 \pm 1.50 \mu \mathrm{mol} / 1, \mathrm{P}<0.001)$. The plasma levels of Hcy in the two groups are illustrated in Fig. 2. Regression analysis was used to evaluate an environmental factor (tobacco smoking) and its possible interaction with the MTHFR gene C677T polymorphism in influencing venous thrombogenesis. No interaction was revealed between the MTHFR genotype and tobacco smoking. Table VI shows the logistic regression analysis of the interaction of tobacco smoking with the MTHFR C677T polymorphism in VTE.

\section{Discussion}

Thrombophilia is defined as a disorder of coagulation that contributes to a predisposition towards thrombosis (11). Although the term thrombophilia has been used to describe arterial thrombosis, its most common usage has been in reference to VTE (12). Thrombophilia is a consequence of acquired and inherited or genetic causes. Acquired causes include conditions such as surgery, cancer and prolonged immobilization, while genetic causes have been linked to the inherited deficiencies of antithrombin $(13)$, protein $C(14,15)$ and protein $S(14,16)$. The identification of the genetic basis of these inherited causes of thrombophilia has changed the way thrombosis and the importance of its genetic component are viewed. Interest in the genetic basis of VTE was accelerated with the subsequent discovery of factor V Leiden (17), prothrombin G20210A (18) and MTHFR C677T (19). The identification of new genetic variants that may either directly or indirectly affect coagulation or the anticoagulant pathway may greatly advance the understanding and clinical management of thrombophilia.

Hyperhomocysteinemia is associated with the occurrence of vascular complications. The significance of hyperhomocysteinemia in predicting vascular complications in various locations has been highlighted by several studies $(20,21)$. The underlying mechanism by which Hcy affects thrombosis is unclear. Hcy, which is formed from methionine, is either remethylated into methionine or catabolized via the vitamin B6-dependent transsulfuration pathway (22). Methionine synthase catalyzes the remethylation of Hcy and requires 5-methyltetrahydrofolate, as a substrate, and vitamin B12, as a co-factor, to function. 5-Methyltetrahydrofolate is produced from the reduction of 5,10-methylenetetrahydrofolate by MTHFR, which is thereby a Hcy metabolism-regulator. However, in the absence of low serum folate, the presence of a 
Table IV. MTHFR C677T polymorphism and VTE risk.

\begin{tabular}{lcccc}
\hline Genotype & $\begin{array}{c}\text { Controls } \\
\mathrm{n}(\%)\end{array}$ & $\begin{array}{c}\text { Cases } \\
\mathrm{n}(\%)\end{array}$ & OR (95\% CI) & $\begin{array}{l}\text { P-value } \\
\text { CC }\end{array}$ \\
\hline CT & $182(41.4)$ & $171(38.9)$ & $0.879(0.653-1.184)$ & 0.440 \\
TT & $190(43.2)$ & $157(35.7)$ & $1.753(1.215-2.529)$ & 0.003 \\
CT+TT & $68(15.5)$ & $269(61.1)$ & $1.110(0.847-1.453)$ & 0.492 \\
\hline
\end{tabular}

Compared with the CC genotype, the TT genotype was significantly correlated with an increased risk of VTE. MTHFR, methylenetetrahydrofolate reductase; VTE, venous thromboembolism; OR, odds ratio; CI, confidence interval.

Table V. Plasma Hcy levels among different genotypes.

\begin{tabular}{|c|c|c|c|c|}
\hline Genotype & Cases & Controls & $\mathrm{t}$ & P-value \\
\hline $\mathrm{CC}$ & $11.35 \pm 1.57$ & $10.03 \pm 1.50$ & 8.078 & $<0.001$ \\
\hline $\mathrm{CT}$ & $11.69 \pm 1.73$ & $10.58 \pm 2.05^{\mathrm{a}}$ & 5.469 & $<0.001$ \\
\hline $\mathrm{TT}$ & $15.87 \pm 2.83^{\mathrm{a}, \mathrm{b}}$ & $13.92 \pm 2.54^{\mathrm{a}, \mathrm{b}}$ & 4.656 & $<0.001$ \\
\hline $\mathrm{CT}+\mathrm{TT}$ & $14.49 \pm 2.51^{\mathrm{a}, \mathrm{b}, \mathrm{c}}$ & $13.28 \pm 2.37^{\mathrm{a}, \mathrm{b}, \mathrm{c}}$ & 5.685 & $<0.001$ \\
\hline $\mathrm{CC}+\mathrm{CT}+\mathrm{TT}$ & $13.05 \pm 2.37^{\mathrm{a}, \mathrm{b}, \mathrm{c}, \mathrm{d}}$ & $11.94 \pm 2.03^{\mathrm{a}, \mathrm{b}, \mathrm{c}, \mathrm{d}}$ & 7.461 & $<0.001$ \\
\hline $\mathrm{F}$ & 106.051 & 100.362 & - & - \\
\hline P-value & $<0.001$ & $<0.001$ & - & - \\
\hline
\end{tabular}

${ }^{\mathrm{a}} \mathrm{P}<0.05$ vs. $\mathrm{CC} ;{ }^{\mathrm{b}} \mathrm{P}<0.05$ vs. $\mathrm{CT}$; ${ }^{\mathrm{c}} \mathrm{P}<0.05$ vs. TT; ${ }^{\mathrm{d}} \mathrm{P}<0.05$ vs. $\mathrm{CT}+\mathrm{TT}$. Hcy, homocysteine.

Table VI. Logistic regression analysis on tobacco usage and MTHFR C677T for interaction in VTE.

\begin{tabular}{|c|c|c|c|c|c|}
\hline Smoking status & Genotype & $\begin{array}{l}\text { Cases } \\
\mathrm{n}(\%)\end{array}$ & $\begin{array}{c}\text { Controls } \\
\mathrm{n}(\%)\end{array}$ & OR $(95 \% \mathrm{CI})$ & P-value \\
\hline \multirow[t]{3}{*}{ Smoking } & $\mathrm{CC}$ & $66(32.5)$ & $83(46.9)$ & 1 & - \\
\hline & $\mathrm{CT}$ & 85 (41.9) & $56(31.6)$ & $1.909(1.196-3.046)$ & 0.009 \\
\hline & $\mathrm{TT}$ & $52(25.6)$ & $38(21.5)$ & $1.721(1.014-2.920)$ & 0.043 \\
\hline \multirow[t]{3}{*}{ Non-smoking } & $\mathrm{CC}$ & $105(44.3)$ & $109(41.4)$ & 1 & - \\
\hline & CT & $72(30.4)$ & $124(47.1)$ & $0.603(0.406-0.895)$ & 0.016 \\
\hline & $\mathrm{TT}$ & $60(25.3)$ & $30(11.4)$ & $2.076(1.242-3.470)$ & 0.007 \\
\hline
\end{tabular}

MTHFR, methylenetetrahydrofolate reductase; VTE, venous thromboembolism; OR, odds ratio; CI, confidence interval.

mutation of the MTHFR gene which is responsible for hyperhomocysteinemia has not been identified as a vascular risk factor (23). The MTHFR 677T allele codes for the thermolabile form of MTHFR, a key enzyme in the conversion pathway of Hcy to methionine. The C677T MTHFR mutation involves the substitution of an alanine residue for a valine, which results in a substantial reduction in its thermolabile enzymatic activity. The C677T MTHFR mutation is a possible genetic contributor to hyperhomocysteinemia.

Gemmati et al (24) reported that there was a high prevalence of homozygotes for the mutated MTHFR allele among cases with VTE disease, suggesting that in selected patients homozygosity for the MTHFR mutation increases the risk of arterial and venous thromboses and that differences in selection criteria for the patient group may be partly responsible for the controversial association of the MTHFR mutation and vascular disease. Couturaud et al (25) reported that the frequency of the C677T mutation MTHFR was $21.8 \%$ in its homozygous state and $34.5 \%$ in its heterozygous state. The OR for having VTE in the presence of the mutation in its homozygous state was 2.9 (95\% CI, 1.0-8.6). Salomon et al (26) suggested that homozygous MTHFR C677T was an independent risk factor for VTE, with an OR of 2.1. Oger et al (27) reported that mild hyperhomocysteinemia, low serum folates and vitamin B12 were associated with VTE independently of each other. In multivariate analysis, VTE was associated with mild hyperhomocysteinemia, low serum folates and vitamin B12. An MTHFR 677TT genotype was not significantly associated 
with VTE (OR, 1.13; 95\% CI, 0.70-1.81). Ray et al (28) reported that the classic MTHFR C677T gene polymorphism is weakly associated with an increased risk of VTE. It is unlikely that the purported correlation between hyperhomocysteinemia and VTE is mediated by this gene defect to a substantial degree, although other unidentified gene polymorphisms may explain this association. The main finding of the present study was that high plasma levels of Hcy and the MTHFR C677T gene polymorphism are significantly associated with VTE pathogenesis. By contrast, there were no significant differences in the frequency of the thermolabile form of MTHFR between diabetic patients and control subjects. Our data suggest an association between the TT genotype and an increased risk for VTE. In the present study, the VTE patients with the TT genotype had higher plasma Hcy levels compared with those with the CC or CT genotype. This result is consistent with those of previous studies and revealed the effect of the MTHFR gene C677T mutation on Hcy levels. The logistic regression analysis in this study demonstrated that the TT genotype was a significant risk factor for VTE. The difference in Hcy levels among the MTHFR genotype implies that the Hcy levels account for the genotypic effect on venous thrombogenesis.

Notably, the majority of the aforemention studies are based are case-control studies. The finding of an association between MTHFR homozygosity and any of these endpoints was not reproduced in the current population-based case-control study. There are several possible explanations for these differences in demographics and risk factor prevalence between previous studies and the present. Alternatively, differences in study design may account for the apparent discrepancy. Clustering of additional risk factors among cases in case-control studies may introduce bias toward a higher risk estimate than in population-based studies.

In conclusion, our data suggest an association between the TT genotype and an increased risk of VTE. The present observations suggest that the C677T mutation of the MTHFR gene, which is known to cause mild hyperhomocysteinemia, is one of the candidate genetic risk factors predisposing to the development of VTE. Whether genetic or environmental risk factors interact with hereditary conditions requires further investigation.

\section{References}

1. Cattaneo M: Hyperhomocysteinemia and venous thromboembolism. Semin Thromb Hemost 32: 716-723, 2006.

2. Božič-Mijovski M: Hyperhomocysteinemia and thrombophilia. Clin Chem Lab Med 48 (Suppl 1): S89-S95, 2010.

3. Aguilar B, Rojas JC and Collados MT: Metabolism of homocysteine and its relationship with cardiovascular disease. J Thromb Thrombolysis 18: 75-87, 2004.

4. Franchini M, Veneri D, Salvagno GL, Manzato F and Lippi G: Inherited thrombophilia. Crit Rev Clin Lab Sci 43: 249-290, 2006.

5. Melo SS, Persuhn DC, Meirelles MS, Jordao AA and Vannucchi H: G1793A polymorphisms in the methylenetetrahydrofolate gene: effect of folic acid on homocysteine levels. Mol Nutr Food Res 50: 769-774, 2006

6. Kumar J, Garg G, Kumar A, et al: Single nucleotide polymorphisms in homocysteine metabolism pathway genes: association of CHDH A119C and MTHFR C677T with hyperhomocysteinemia. Circ Cardiovasc Genet 2: 599-606, 2009
7. Legnani C, Palareti G, Grauso F, et al: Hyperhomocyst(e)inemia and a common methylenetetrahydrofolate reductase mutation (Ala223Val MTHFR) in patients with inherited thrombophilic coagulation defects. Arterioscler Thromb Vasc Biol 17: 2924-2929, 1997.

8. D'Angelo A, Mazzola G and Fermo I: Gene-gene and gene-environment interactions in mild hyperhomocysteinemia. Pathophysiol Haemost Thromb 33: 337-341, 2003.

9. Frosst P, Blom HJ, Milos R, et al: A candidate genetic risk factor for vascular disease: a common mutation in methylenetetrahydrofolate reductase. Nat Genet 10: 111-113, 1995.

10. Frederiksen J, Juul K, Grande P, Jensen GB, Schroeder TV, Tybjaerg-Hansen A and Nordestgaard BG: Methylenetetrahydrofolate reductase polymorphism (C677T), hyperhomocysteinemia, and risk of ischemic cardiovascular disease and venous thromboembolism: prospective and casecontrol studies from the Copenhagen City Heart Study. Blood 104: 3046-3051, 2004

11. Khare A, Ghosh K, Kulkarni B and Mohanty D: Thrombophilia: hereditary and acquired in cardiovascular disease. Haematologia (Budap) 32: 293-311, 2002.

12. Greer IA: Inherited thrombophilia and venous thromboembolism. Best Pract Res Clin Obstet Gynaecol 17: 413-425, 2003.

13. Martinelli I: Risk factors in venous thromboembolism. Thromb Haemost 86: 395-403, 2001.

14. Bereczky Z, Kovács KB and Muszbek L: Protein C and protein S deficiencies: similarities and differences between two brothers playing in the same game. Clin Chem Lab Med 48 (Suppl 1): S53-S66, 2010.

15. Castoldi E and Rosing J: APC resistance: biological basis and acquired influences. J Thromb Haemost 8: 445-453, 2010.

16. Slavik L, Krcova V, Hlusi A, et al: Molecular pathophysiology of thrombotic states and their impact to laboratory diagnostics. Biomed Pap Med Fac Univ Palacky Olomouc Czech Repub 153: 19-25, 2009.

17. Simioni P, Scudeller A and Girolami A: Factor V Leiden and thrombophilia. N Engl J Med 332: 1382, 1995.

18. Nguyen A: Prothrombin G20210A polymorphism and thrombophilia. Mayo Clin Proc 75: 595-604, 2000.

19. Hoţoleanu C, Porojan-Iuga M, Rusu ML and Andercou A: Hyperhomocysteinemia: clinical and therapeutical involvement in venous thrombosis. Rom J Intern Med 45: 159-164, 2007.

20. Van Oijen MG, Vlemmix F, Laheij RJ, Paloheimo L, Jansen JB and Verheugt FW: Hyperhomocysteinaemia and vitamin B12 deficiency: the long-term effects in cardiovascular disease. Cardiology 107: 57-62, 2007.

21. Aksoy M, Basar Y, Salmayenli N, et al: Hyperhomocysteinemia in patients with arterial occlusive disease. Surg Today 36: 327-331,2006.

22. Ramakrishnan S, Sulochana KN, Lakshmi S, Selvi R and Angayarkanni N: Biochemistry of homocysteine in health and diseases. Indian J Biochem Biophys 43: 275-283, 2006.

23. Cortese C and Motti C: MTHFR gene polymorphism, homocysteine and cardiovascular disease. Public Health Nutr 4: 493-497, 2001

24. Gemmati D, Serino ML, Trivellato C, Fiorini S and Scapoli GL: C677T substitution in the methylenetetrahydrofolate reductase gene as a risk factor for venous thrombosis and arterial disease in selected patients. Haematologica 84: 824-828, 1999.

25. Couturaud F, Oger E, Abalain JH, et al: Methylenetetrahydrofolate reductase $\mathrm{C} 677 \mathrm{~T}$ genotype and venous thromboembolic disease. Respiration 67: 657-661, 2000.

26. Salomon O, Steinberg DM, Zivelin A, et al: Single and combined prothrombotic factors in patients with idiopathic venous thromboembolism: prevalence and risk assessment. Arterioscler Thromb Vasc Biol 19: 511-518, 1999.

27. Oger E, Lacut K, Le Gal G, et al; EDITH COLLABORATIVE STUDY GROUP: Hyperhomocysteinemia and low B vitamin levels are independently associated with venous thromboembolism: results from the EDITH study: a hospital-based case-control study. J Thromb Haemost 4: 793-799, 2006.

28. Ray JG, Shmorgun D and Chan WS: Common C677T polymorphism of the methylenetetrahydrofolate reductase gene and the risk of venous thromboembolism: meta-analysis of 31 studies. Pathophysiol Haemost Thromb 32: 51-58, 2002. 